\title{
Assessment of Soil Compaction under Center Pivot Irrigation Systems and its Effect on Crop Performance
}

\author{
Khalid Ali Al-Gaadi \\ Department of Agricultural Engineering, Precision Agriculture Research Chair, \\ College of Food and Agriculture Sciences, \\ King Saud University, P.O. Box 2460, Riyadh 11451, Saudi Arabia
}

Received 2012-10-01, Revised 2012-10-01; Accepted 2013-03-12

\begin{abstract}
A field study on two 12.5 ha plots cultivated with wheat and alfalfa was conducted to determine Soil Compaction (SC), its spatial variability and its effect on crop performance under center pivot irrigation systems. Considering compaction at two tested soil depths, results revealed that the soil of the alfalfa plot exhibited significantly ( $\mathrm{p}<0.01$ and $\mathrm{p}<0.05$ for 0 to $10 \mathrm{~cm}$ and 0 to $30 \mathrm{~cm}$ soil depth, respectively) higher compaction values (an average of 1730.328 and $2329.604 \mathrm{kPa}$, respectively) compared to those exhibited by the soil of the wheat plot (averaging at 1339.685 and $2088.903 \mathrm{kPa}$, respectively). Significant spatial variation of SC was observed within each of the tested plots. SC around pivot wheel tracks was also investigated at a soil depth of 0 to $30 \mathrm{~cm}$ for $5.5 \mathrm{~m}$ wide strips on both sides of the tracks. Results revealed that the Coefficient of Variation (CV) of the SC around the tracks was 9.33 and $16.53 \%$ for alfalfa and wheat plots, respectively, suggesting that the SC was not laterally influenced by the wheel tracks. The effect of SC on crop performance, expressed as the Normalized Difference Vegetation Index (NDVI), was investigated on the two plots. Results showed that the NDVI was, in general, inversely proportional to the SC. For both crops, the NDVI was more affected by SC at the top soil layer $(0-10 \mathrm{~cm}$ depth). Moreover, the alfalfa crop was shown to be significantly influenced by the SC (an average $R^{2}$ value of 0.3165 and $P$ value of 0.0287), unlike the wheat crop (an average $R^{2}$ value of 0.0725 and $P$ value of 0.4646 ).
\end{abstract}

Keywords: Precision Farming, Soil Compaction, NDVI, Center Pivot Irrigation, Mapping, Saudi Arabia

\section{INTRODUCTION}

In the kingdom of Saudi Arabia, most commercial crops are grown on fields of large areas (vary from 15 to $50 \mathrm{ha}$ ) and irrigated using center pivot irrigation systems. These fields of such large areas were observed to have spatial variability in soil properties and crop yield. Understanding and assessing the spatial variability of soil characteristics, such as soil compaction and their effect on yield is a crucial step towards the appropriate application of precision agriculture technology.

Soil compaction, which refers to the reduction in soil macro-pores and the increase in both soil density and soil strength, is characterized as one of the key land degradation processes. It imposes detrimental effects on crop production as it creates a poor environment for root growth, reduces water infiltration and increases runoff, hence, soil erosion. Richard et al. (1999) reported that soil compaction caused by the passage of vehicles resulted in important economic and ecological consequences, such as poor crop productivity due to problems of crop establishment and root growth and excessive soil erosion due to reduced water infiltrability. According to Bober et al. (1996), wheel traffic from heavy vehicles can compress soils to varying degrees throughout the plant root zone, often causing increased mechanical strength and decreased air and water permeability. This condition can impede root elongation and significantly reduce crop growth and yield. The detrimental effects of soil compaction on crop performance have been reported by a number of researchers. Vermeulen et al. (2010) reported the factors associated with soil compaction that 
could reduce crop growth potential, which included water infiltration, plant available water capacity, oxygen supply and de-nitrification. Most studies have shown that crop yields have been negatively affected by soil compaction. A study by Pritchard et al. (2009) revealed that compacted layers affected crops directly as plant roots encountered high physical resistance and indirectly by causing poor soil aeration, lowering the access of plants to soil water and increasing water logging. In addition, Lipiec et al. (2003) concluded that an increase in soil compactness resulted in decreased root size, higher concentration of roots in the upper soil, lower rooting depth and a greater distance between the nearest roots. They also stated that nutrient uptake and effectiveness of fertilization were reduced by soil compaction. A similar study conducted by Isaac et al. (2002), where Cone Index (CI) data was used to explain corn yield variation within a field. They found that the mean CI throughout the top $76.2 \mathrm{~cm}$ soil profile was appropriate to explain yield variation $\left(\mathrm{R}^{2}=0.70\right)$. They also concluded that the maximum CI values at or above 1.4 $\mathrm{MPa}$ resulted in below average yields for $89 \%$ of the readings exceeding this limit. Another study was conducted by Petcu and Petcu (2006) to investigate the influence of soil compaction on sunflower production. Their results showed that the plant height and leaf area were reduced by compaction due to deteriorated soil conditions for root growth. The root biomass was lowered by $16-33 \%$ in compacted soil compared to non-compacted one. They concluded that soil compaction was a major cause of the reduction of biomass accumulation in the plant root and the grain yield per plant.

Sandy soil is characterized as the major soil class that dominates agricultural soils in the Kingdom of Saudi Arabia. The specific behavior of sandy soils towards soil compaction was described by Bruand et al. (2005). They stated that the structure of sandy soils could be easily affected by mechanical compaction because of the possibility of the re-arrangement of soil particles, due to small cohesion among them, when subjected to mechanical compaction. Moreover, they estimated the critical compaction values that could severely restrict root growth to vary from 1.0 to $40 \mathrm{MPa}$, depending on soil type, water content and crop.

Unlike traditional managements of soil and crop production, precision farming refers to the map-based approach for site-specific management to rapidly characterize the spatial variability of soil physical and chemical properties at different depths and crop yield distribution at different field scales (Sun et al., 2011). Therefore, proper site specific assessment of soil compaction across a specific field enables optimal field management practices, such as land preparation and irrigation. Soil compaction mapping is a useful tool to illustrate compaction variability within a field, which can cause considerable yield variations. The importance of soil compaction mapping was emphasized by Domsch et al. (2006). They stated that it was generally not possible to avoid the creation of hard pan layers, which could cause negative effects on crop growth and yields, with either conventional or conservation tillage. They added that loosening these layers greatly reduced these effects on crops and yields. They also stated that unnecessarily deep loosening was expensive and may lead to further degradation of the physical condition of the soil. Sitespecific soil loosening was reported by the same authors to be dependent on the detection of local hard pans using soil strength measurements, they reported. Efficient and cost-effective implementation of precision tillage could be achieved by the use of supplementary information, such as remotely sensed images, yield maps and farmers' knowledge of fields (Wells et al., 2001).

In a center pivot irrigation system, the pivot is repeatedly and continually driven on a predetermined wheel tracks. This action leads to the development of wheel ruts as a result of the repeated trafficking of the tower wheels over wet/moist soil (Tatura, 2005). Information of the lateral effect of pivot wheels on soil compaction is limited. Therefore, part of this study will investigate the effect of center pivot wheels on compaction of soil around those wheels.

\subsection{Objectives}

The main goal of this study was to assess the spatial variability of soil compaction for areas under center pivot irrigation systems and investigate its effect on crop performance. The specific objectives, however, are as follows:

- To determine Soil Compaction (SC) of the study area and develop SC maps

- To compare SC patterns in plots cultivated with wheat and alfalfa crops

- To investigate SC patterns around pivot wheel tracks

- To develop Normalized Difference Vegetation Index (NDVI) maps of the two crops

- To study the effect of SC on crop performance based on the determined NDVI values

\section{MATERIALS AND METHODS}

\subsection{Experimental Site}

The experimental field work was performed in the year 2012 on two plots under center pivot irrigation systems in the Eastern region of the Kingdom of Saudi Arabia. 


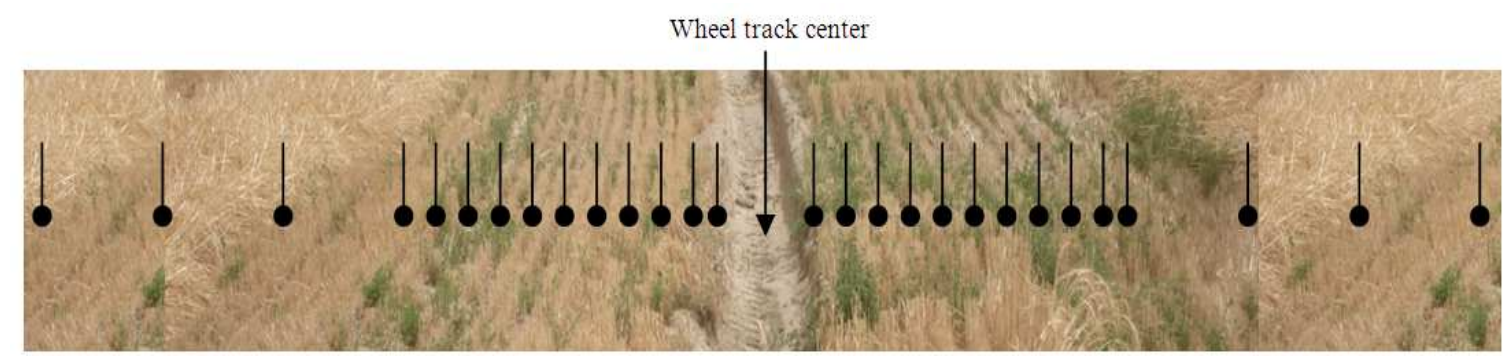

Fig. 1. Soil compaction sample points around pivot wheel tracks

The plots were located at the Todhia farm $\left(24^{\circ} 10^{\prime} 21^{\prime \prime} \mathrm{N}\right.$ and $48^{\circ} 04^{\prime} 04^{\prime \prime}$ E) with an area of 12.5 ha/plot. These plots (each occupying three sectors) were parts of two fields with an area of $50 \mathrm{ha} /$ field. One field was under alfalfa cultivation and was marked as Pivot TE10; however, the other field was under wheat cultivation and was marked as Pivot TE11. The soil type of the test plots was characterized as sandy loam.

\subsection{Generation of Soil Compaction Maps}

Soil Penetration Resistance (PR) was used as an indicator of Soil Compaction (SC) according to Tracy and Zhang (2008) and was measured using a Field Scout SC 900 compaction meter Spectrum Technologies Inc, 2009. SC (PR) measurements for the test plots were collected from the top $10 \mathrm{~cm}$ of the soil profile and from the soil depth of 0 to $30 \mathrm{~cm}$ at average soil moisture content values of 12.70 and $12.45 \%$ for pivots TE10 and TE11, respectively. Stratified random sampling technique was used for field soil compaction data collection. Measurements of SC were taken at sample points across the sectors (strata) in each of the two experimental plots with a sampling density (samples/ha) of 5.36 and 5.04 for pivots TE10 and TE11, respectively. The coordinates of each filed data point were determined using GPS OmniSTAR 9200-G2 receiver with an accuracy of $0.20 \mathrm{~m}$ (OmniStar, 2010).

In order to generate soil compaction maps, geostatistical interpolation (kriging) tool of Arc GIS Software ESRI Inc, 2010 was used. Interpolation technique was utilized to predict the soil compaction values of cells at all locations that lacked sampled points (Childs, 2004).

\subsection{Normalized Difference Vegetation Index (NDVI)}

The Normalized Difference Vegetation Index (NDVI) is an important indicator used to measure and monitor plant growth, vegetation cover and biomass production from multispectral satellite data (Tucker et al.,
2001). The NDVI image maps used for this study were prepared using spectral data in the visible and near infrared regions of the electromagnetic spectrum. The NDVI was calculated according to Rundquist and Harrington (2000) using Equation 1:

$\mathrm{NDVI}=\frac{\mathrm{NIR}-\mathrm{R}}{\mathrm{NIR}+\mathrm{R}}$

where, NIR is near infrared channel and $\mathrm{R}$ is red channel of the respective sensors of the imaging satellite platforms.

\subsection{Satellite Data Based NDVI Map}

Cloud free ASTER imageries of path 165 were acquired on February 17 and March 4th, 2012 as a part of a study conducted by Patil and Al-Gaadi (2012). Images were subjected to radiometric calibration and geometric correction using header information, such as ASTER sensor coefficients, elevation angle and geo-location utilizing ERDAS Imagine software program Leica, Inc., 2011. The radiometric calibration was conducted using the ASTER radiance to reflectance conversion model (Smith, 2007; Yuksel et al., 2008; Lu et al., 2002).

NDVI was calculated for ASTER images using band 3 (NIR) and band 2 (R) (Bawazir et al., 2009). Vigorously growing healthy vegetation exhibited a low red-light and high near-infrared reflectance and hence, high NDVI values. This relatively simple algorithm presented in equation 1 produced output values in the range of -1 to +1 . Increasing positive NDVI values indicated increased volume of green vegetation. A zero (0) value indicated no vegetation; however, a value close to $+1(0.8$ to 0.9$)$ indicated the highest possible density of green leaves.

\subsection{Compaction Due to Pivot Wheel Tracks}

The pivot is repeatedly and continually driven on a predetermined wheel tracks, therefore, an investigation 
of SC around these tracks was carried out. SC was measured for three tracks in each of the two plots at a soil depth of 0 to $30 \mathrm{~cm}$. For each track, sampling was started, on both sides of the track, at a distance of $50 \mathrm{~cm}$ from the center of the wheel track spreading out laterally by an incremental distance of $0.2 \mathrm{~m}$ up to $2.5 \mathrm{~m}$ and then by an increment of $1.0 \mathrm{~m}$ up to $5.5 \mathrm{~m}$. As a result, a total of 14 data points on each side of the track were acquired (Fig. 1).

\section{RESULTS AND DISCUSSION}

\subsection{Soil Compaction Analysis and Mapping}

Statistical analysis was performed to compare soil compaction values using one-way analysis of variance offered by the SPSS software program, version 20 IBM Inc., 2011. For the soil depth of 0 to $10 \mathrm{~cm}$, significantly higher SC values $(p<0.01)$ were associated with the alfalfa plot (average of $1730.328 \mathrm{kPa}$ ) compared to those associated with the wheat plot (average of $1339.685 \mathrm{kPa}$ ). The same result was observed at the soil depth of 0 to 30 $\mathrm{cm}$, where significant differences $(\mathrm{p}<0.05)$ in soil compaction between alfalfa (average of $2329.604 \mathrm{kPa}$ ) and wheat (average of $2088.903 \mathrm{kPa}$ ) plots were recorded. This was attributed to the fact that the alfalfa was a multi-cut crop where more machine traffic occurred on the plot, hence, more soil compaction (Rechel et al., 1991). For the two plots and at both soil depths, the range of SC, along with the averages, is presented in Fig. 2.

A wide range of SC of more than $1400 \mathrm{kPa}$ was recorded for the soil in both plots and at both soil depths, except in the wheat plot at 0 to $10 \mathrm{~cm}$ soil depth, where a range of $1067 \mathrm{kPa}$ was recorded. These wide ranges suggested that the SC was a spatially variable soil characteristic that needed to be considered when applying precision agriculture technology.

Geographical Information System (GIS) maps of SC at the two soil depths were developed, using the ARC GIS software program ESRI Inc, 2010, for the alfalfa and wheat plots as shown in Fig. 3 and 4, respectively. The distribution patterns of soil compaction values within each of the two tested plots showed high significant differences $(p<0.01)$ as shown in Table 1. In Fig. 3 and 4, it can be seen that higher SC values were associated, in both plots, with the soil depth of 0 to 30 $\mathrm{cm}$. Moreover, the SC was shown to be spatially variable within the test plots.

The above results indicated that significant compaction spatial variability occurred within different locations of the study plots. The interaction of several dynamic soil processes, such as swelling and shrinking, can significantly add to the heterogeneity of agricultural soils causing more soil compaction. In addition to the heterogeneity in agricultural soils, high compaction levels can be attributed to the implementation of intensive agricultural production systems on the study fields, uneven distribution of the frequent movement of agricultural machines, poor tillage procedures and poor timing of field operations. Implementation of a site specific tillage technique can be considered as a suitable management process to avoid such variation in soil compaction levels in the same field.

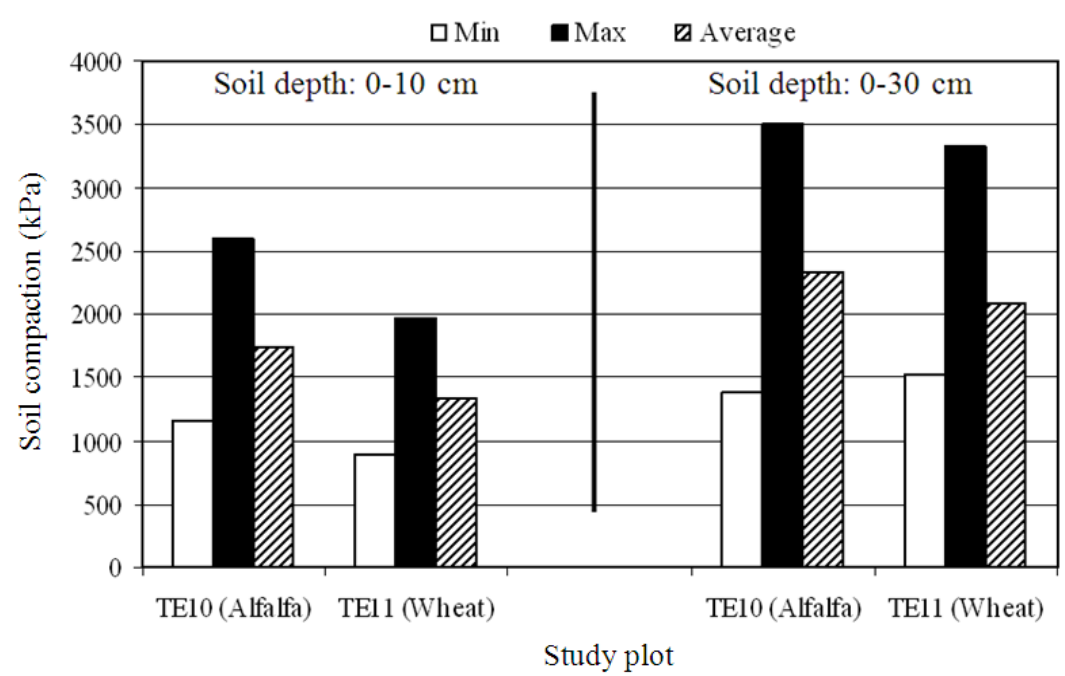

Fig. 2. Soil compaction status for the study plots 
Khalid Ali Al-Gaadi / American Journal of Agricultural and Biological Sciences 8 (1): 54-66, 2013

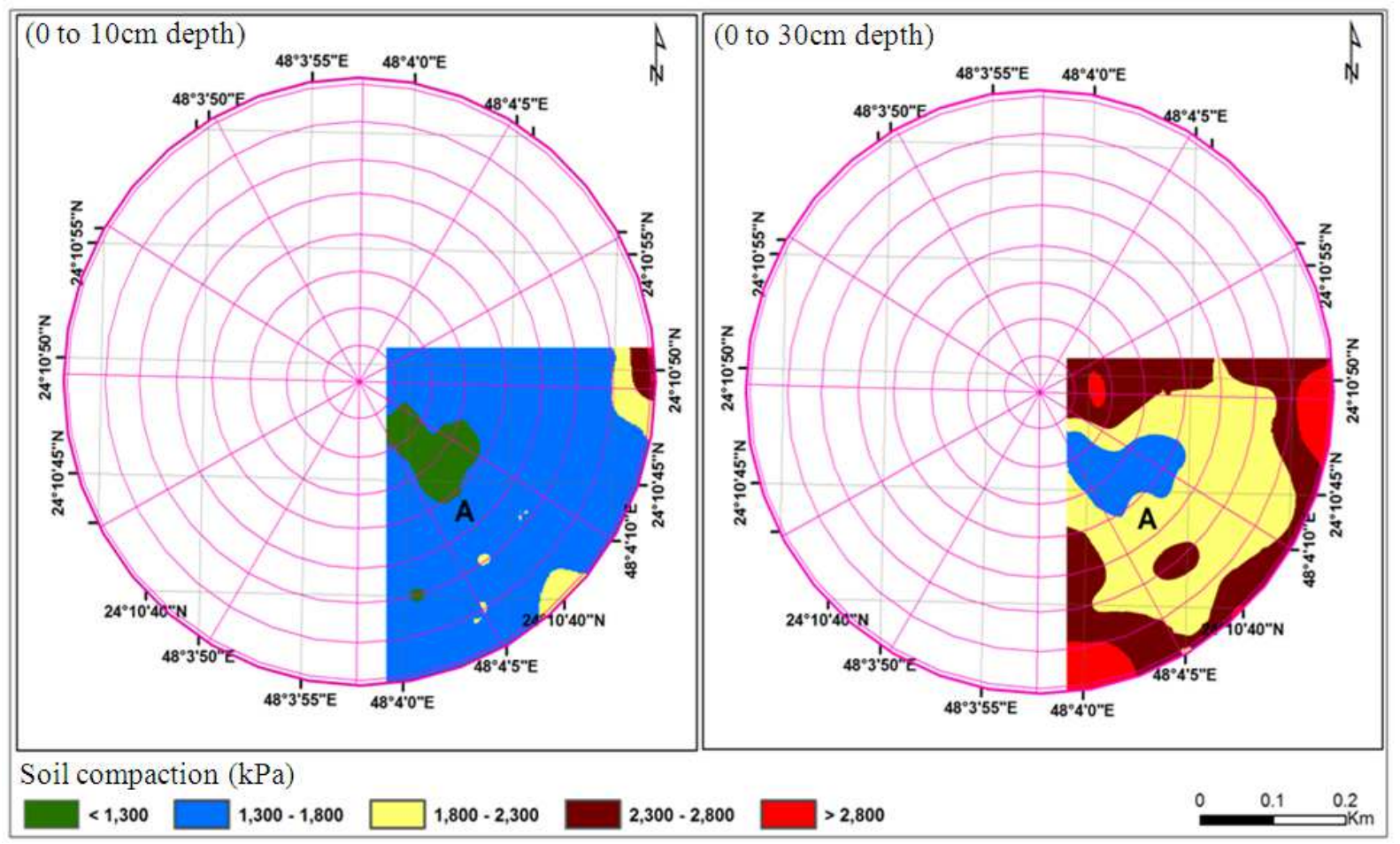

Fig. 3. Alfalfa plot soil compaction map

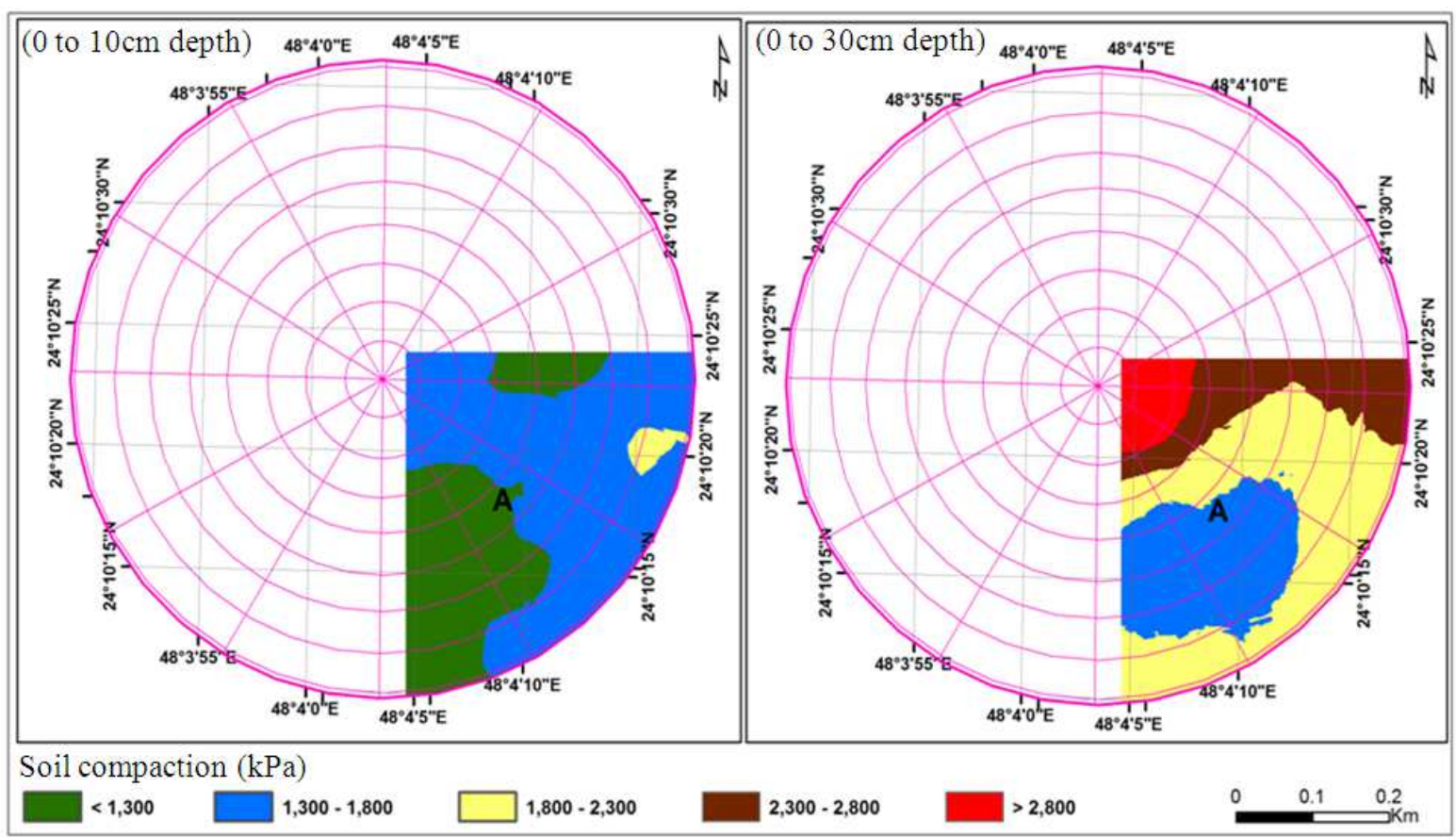

Fig. 4. Wheat plot soil compaction map 


\subsection{Soil Compaction around Pivot Wheel Tracks}

At each sample point, SC values from three tracks were averaged for each plot and depicted in Fig. 5 and 6 for alfalfa and wheat plot, respectively. As shown in these figures, there was no specific trend in the average SC values around the pivot wheel tracks. The values of the Coefficient of Variation (CV) of the average $\mathrm{SC}$ values in Fig. 5 and 6 were calculated at 9.33 and $16.53 \%$ for alfalfa and wheat plots, respectively. These low CV values suggested that there was no lateral significant influence of the pivot wheels on soil compaction.

This conclusion was in agreement with the results of the study conducted by Braunack et al. (1995) on a cracking clay soil, where cone index measurements indicated that there was no lateral spread of compaction from the traffic lanes in the controlled traffic system. Richard et al. (1999) studied SC on a loamy soil due to traffic and stated that the geometry of the severely compacted areas under wheel tracks was bulb-shaped and the area could be approximated by a half-ellipse. Regardless of the soil type, studies have proven that the traffic had no lateral effect on the compaction of the surrounding soil.

\subsection{Effect of Soil Compaction on Crop Performance}

The influence of Soil Compaction (SC) on crop performance based on the Normalized Difference Vegetation Index (NDVI) was investigated for the two test plots. NDVI values for the sector marked A, which occupied an area of 4.19 ha, in Fig. 3 and 4 were taken from a study conducted by Patil and AlGaadi (2012). The NDVI values were acquired for the two crops at two different growth stages dated February 17 and March 4, 2012.

To reveal the relationship between SC and crop NDVI, the measured SC values at both soil depths of 0 to 10 and 0 to $30 \mathrm{~cm}$ were plotted against the NDVI values acquired on both dates for the selected sectors of the alfalfa and wheat plots as shown in Fig. 7 and 8, respectively. For the alfalfa crop, the NDVI was found to be inversely proportional to the SC at both soil depths and on both dates, presenting a definite negative relationship between the two variables. This was attributed to the fact that the alfalfa crop was sensitive to poor drainage and restricted root growth due to soil compaction (Hannaway and Larson, 2004).

The significant relationship between alfalfa NDVI and SC is represented by the $\mathrm{R}^{2}$ and the Probability (P) values shown in Table 2 . Moreover, higher values of correlation between NDVI and SC were observed for the alfalfa at the soil depth of 0 to $10 \mathrm{~cm}$ compared to those at the soil depth of 0 to $30 \mathrm{~cm}$ (Table 2). This was attributed to the higher influence of the compacted top soil surface on the movement and uptake of soil water and nutrients (Lipiec, 2012). For the wheat crop, data analysis revealed that there was no definite logical trend in the relationship between the crop NDVI and SC as shown in Fig. 8. In addition, the low $\mathrm{R}^{2}$ and high $\mathrm{P}$ values presented in Table 2 affirmed that the relationship between wheat NDVI and SC was not significant.

The influence of SC on crop performance was observed to be significantly different depending on the response of each crop to SC. These results were in line with the findings of the study conducted by Kulkarni and Bajwa (2005), where it was stated that the effect of compaction on plant spectral response was significant in Green NDVI. They also showed that soil compaction at $15.24 \mathrm{~cm}$ depth produced a significant effect on cotton yield $\left(\mathrm{R}^{2}\right.$ value of 0.53 at $\left.\mathrm{p}<0.05\right)$. On the other hand, Kulkarni et al. (2010) concluded that the NDVI presented a potential factor that could indicate soil compaction as it was significantly correlated to compaction parameters on a single date of data collection.

To provide a visual representation of the spatial relationship between NDVI and SC, NDVI-based GIS maps were produced for the sector marked A in Fig. 3 and 4, using ARC GIS software program ESRI Inc, 2010 , for the two crops on both dates. These maps were then overlaid on the corresponding SC maps at both soil depths as shown in Fig. 9 and 10 for the alfalfa crop and 11 and 12 for the wheat crop. As a general observation, higher compaction values of more than $2300 \mathrm{kPa}$ appeared on the maps of the two crops at the soil depth of 0 to $30 \mathrm{~cm}$. In Fig. 9-12, the limited number of compaction zones produced at the soil depth of 0 to 10 $\mathrm{cm}$ (mostly two zones only) limited the use of these data to show the spatial association of NDVI with SC. However, at the soil depth of 0 to $30 \mathrm{~cm}$, more compaction zones were produced for the two crops (Fig. 9-12) and were used to reveal the spatial correlation of the two parameters (NDVI and SC). For the alfalfa crop at the soil depth of 0 to $30 \mathrm{~cm}$, more association of high NDVI with low SC was observed with the NDVI data acquired on February 17, 2012 compared to that noted with March 4, 2012 data. For February data, $47.22 \%$ of the area covered by the highest NDVI values (ranging from 0.325 to 0.350 ) was associated with low SC values of equal or less than $1800 \mathrm{kPa}$ (Fig. 9 and 10 and Table 3). The association became lower when considering March data, where the percentage dropped to only $15.24 \%$. This could be attributed to the fact that at that growth stage, the crop was not affected by SC at the considered soil depth range, as the most critical growth stages for alfalfa are immediately after cuttings (USDA, 1997), which corresponded to February data. 


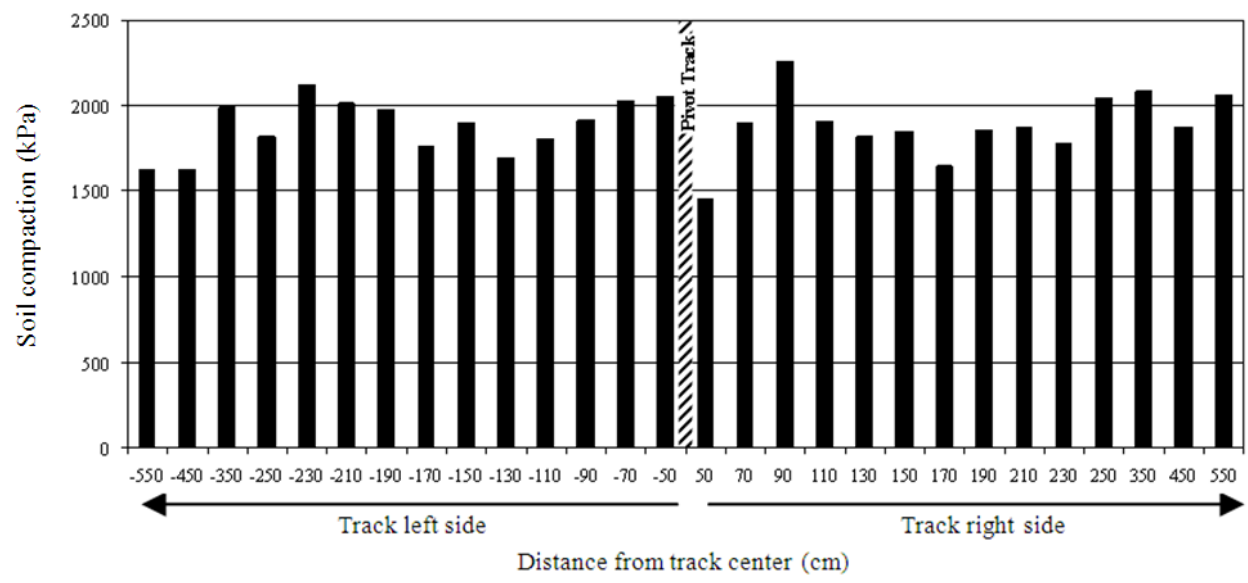

Fig. 5. Soil compaction around wheel tracks for the alfalfa plot

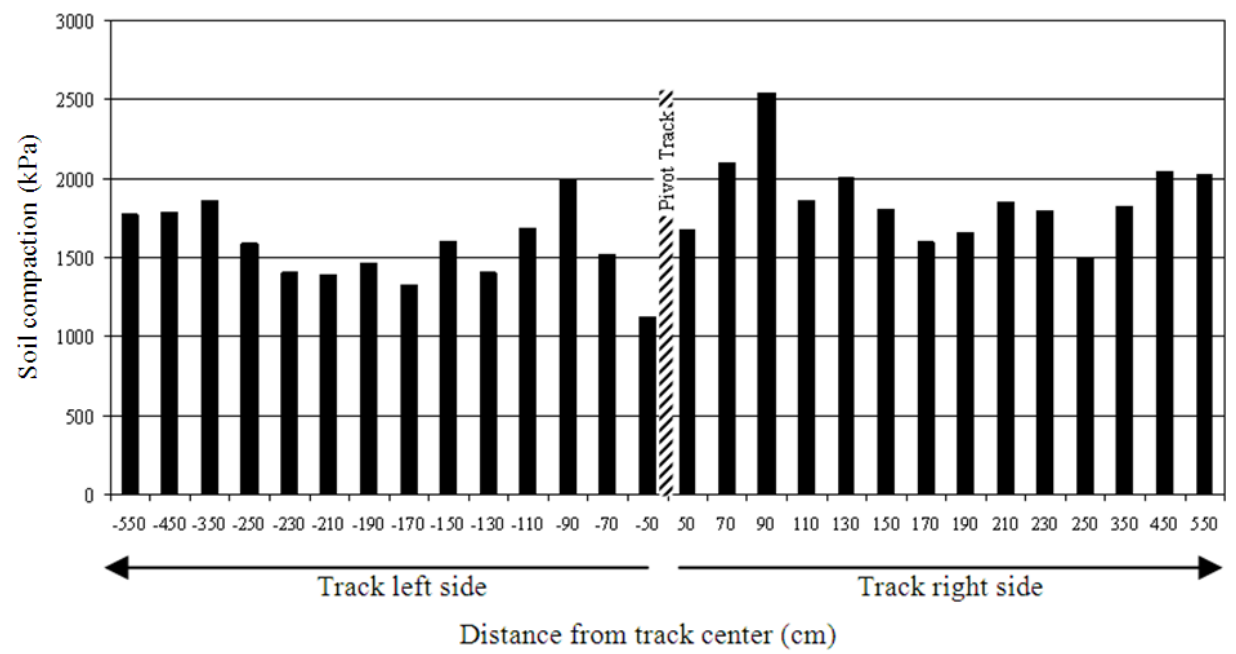

Fig. 6. Soil compaction around wheel tracks for the wheat plot

Table 1. Average soil compaction $(\mathrm{kPa})$ for all zones of the two test plots.

\begin{tabular}{lllllll}
\hline Test plot & Soil depth $(\mathrm{cm})$ & Zone1 & Zone2 & Zone3 & Zone4 & Zone5 \\
\hline \multirow{2}{*}{ TE10 } & $0-10$ & $(<1300 \mathrm{kPa})$ & $(1300-1800 \mathrm{kPa})$ & $(1800-2300 \mathrm{kPa})$ & $(2300-2800 \mathrm{kPa})$ & $(>2800 \mathrm{kPa})$ \\
& $0-30$ & $1245.267^{\mathrm{a}^{*}}$ & $1574.891^{\mathrm{b}}$ & $2071.138^{\mathrm{c}}$ & $2507.733^{\mathrm{d}}$ & --- \\
TE11 & $0-10$ & --- & $1654.895^{\mathrm{b}}$ & $2035.746^{\mathrm{c}}$ & $2529.919^{\mathrm{d}}$ & $3059.831^{\mathrm{e}}$ \\
& $0-30$ & $1087.829^{\mathrm{a}}$ & $1528.982^{\mathrm{b}}$ & $1866.800^{\mathrm{c}}$ & --- & --- \\
& --- & $1639.047^{\mathrm{b}}$ & $2040.161^{\mathrm{c}}$ & $2455.705^{\mathrm{d}}$ & $3084.463^{\mathrm{e}}$ \\
\hline
\end{tabular}

* Values followed by the different letters indicate significant differences.

Table 2. $\mathrm{R}^{2}$ and $\mathrm{P}$ values for SC- NDVI correlations

\begin{tabular}{|c|c|c|c|c|c|c|c|c|}
\hline \multirow[b]{3}{*}{ ASTER image date } & \multicolumn{4}{|c|}{ TE10 (Alfalfa) } & \multicolumn{4}{|c|}{ TE11 (Wheat) } \\
\hline & \multicolumn{2}{|c|}{$0-10 \mathrm{~cm}$} & \multicolumn{2}{|c|}{$0-30 \mathrm{~cm}$} & \multicolumn{2}{|c|}{$0-10 \mathrm{~cm}$} & \multicolumn{2}{|c|}{$0-30 \mathrm{~cm}$} \\
\hline & $\mathrm{R}^{2}$ & $\mathrm{P}$ & $\mathrm{R}^{2}$ & $\mathrm{P}$ & $\mathrm{R}^{2}$ & $\mathrm{P}$ & $\mathrm{R}^{2}$ & $\mathrm{P}$ \\
\hline 17 Feb., 2012 & 0.337 & 0.013 & 0.247 & 0.039 & 0.166 & 0.200 & 0.021 & 0.662 \\
\hline 04-Mar, 2012 & 0.296 & 0.021 & 0.240 & 0.042 & 0.069 & 0.421 & 0.034 & 0.576 \\
\hline
\end{tabular}


Khalid Ali Al-Gaadi / American Journal of Agricultural and Biological Sciences 8 (1): 54-66, 2013

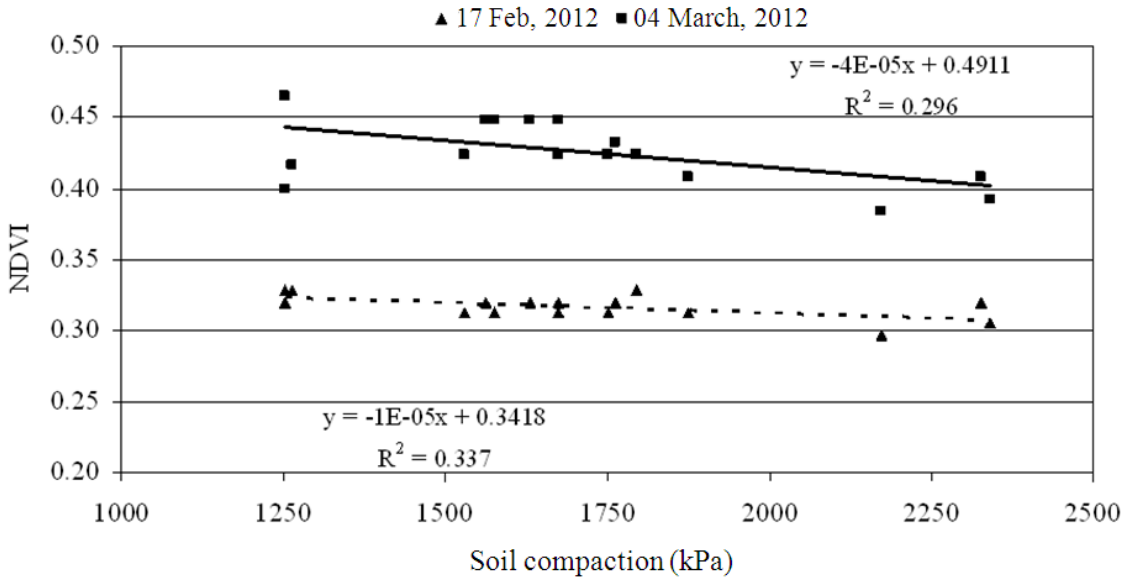

(a)

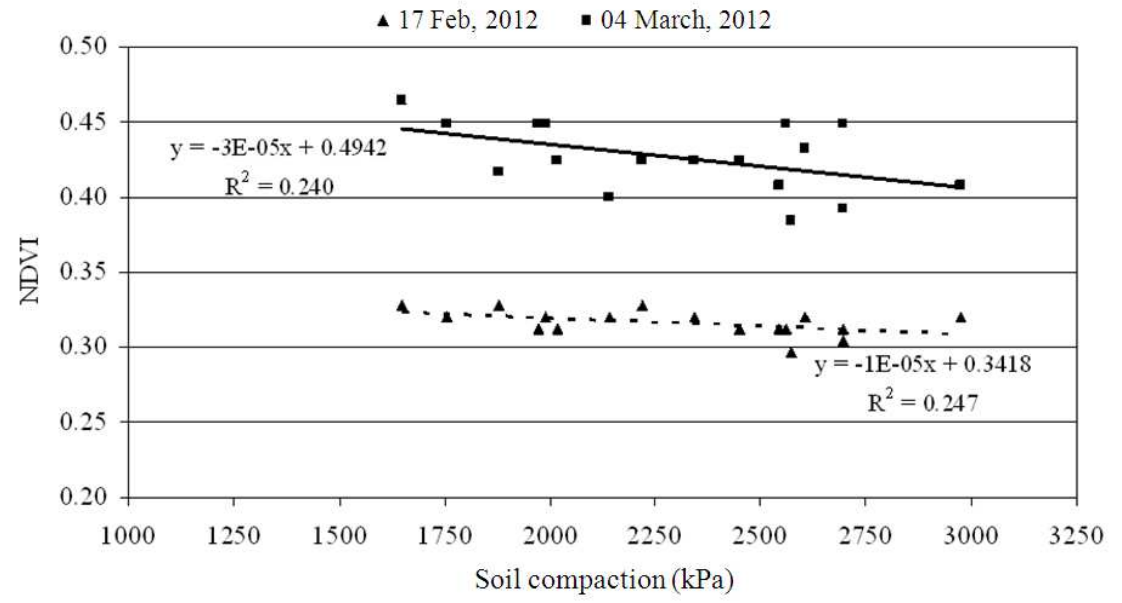

(b)

Fig. 7. Alfalfa NDVI versus soil compaction at a soil depth of (a) 0 to $10 \mathrm{~cm}$ and (b) 0 to $30 \mathrm{~cm}$

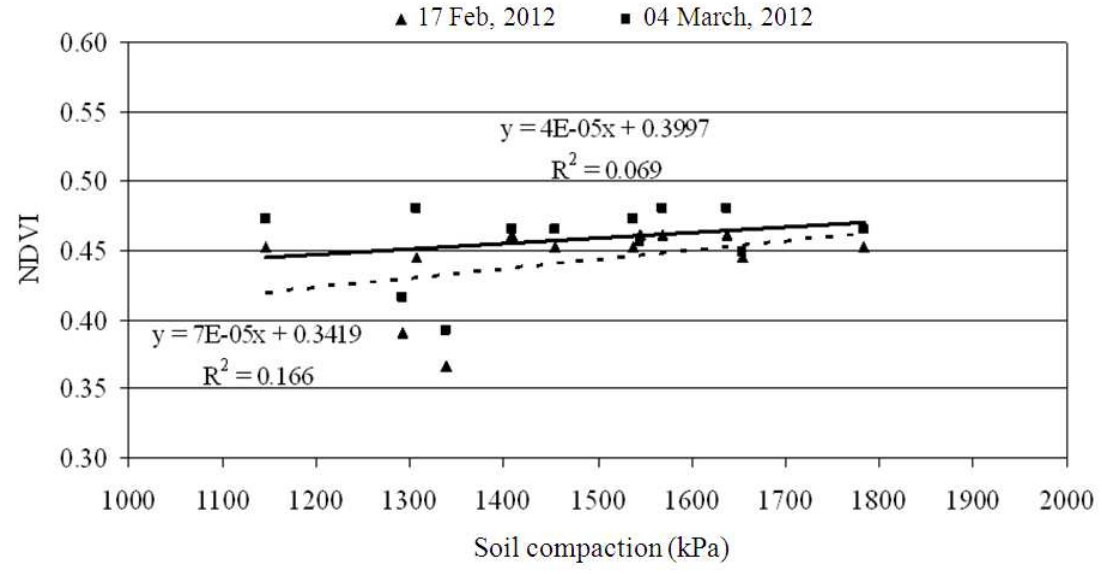

(a) 
Khalid Ali Al-Gaadi / American Journal of Agricultural and Biological Sciences 8 (1): 54-66, 2013

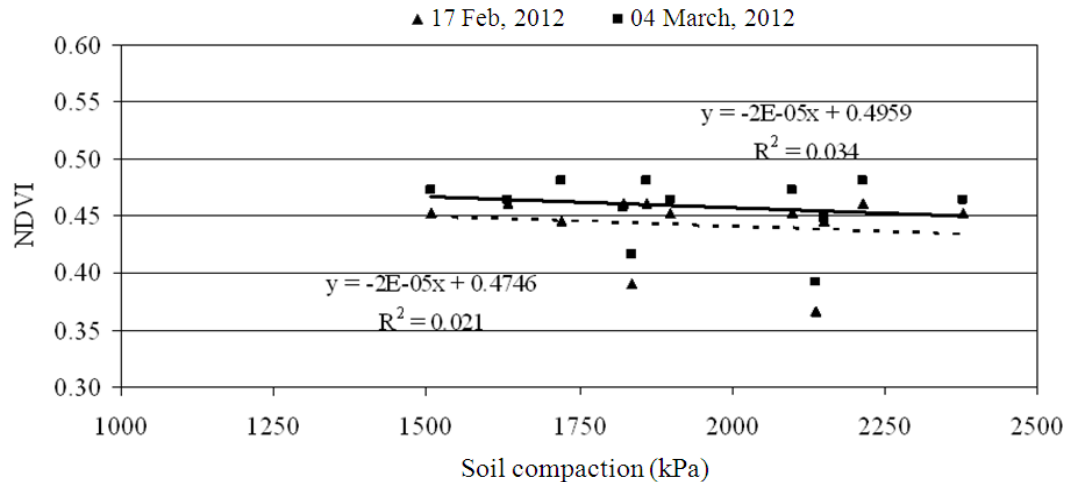

(b)

Fig. 8. Wheat NDVI versus soil compaction at a soil depth of (a) 0 to $10 \mathrm{~cm}$ and (b) 0 to $30 \mathrm{~cm}$

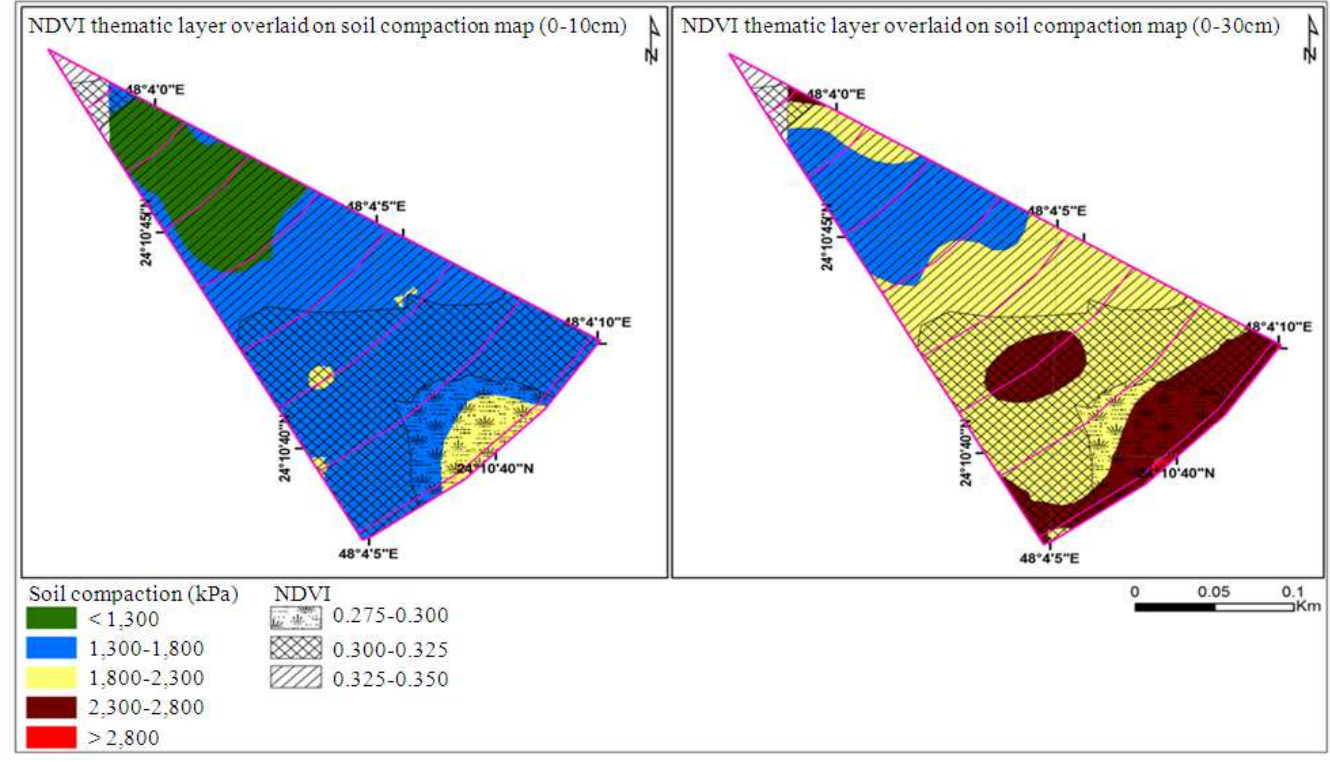

Fig. 9. Alfalfa February NDVI values overlaid on SC map

Table 3. Soil compaction (SC) and NDVI intersected area statistics for alfalfa plot (TE10)

\begin{tabular}{|c|c|c|c|c|c|c|c|c|c|c|c|c|c|}
\hline \multirow[b]{4}{*}{ Soil depth } & \multirow[b]{4}{*}{ SC zones } & \multicolumn{6}{|l|}{$17-F e b-12$} & \multicolumn{6}{|l|}{ 04-Mar-12 } \\
\hline & & \multirow{2}{*}{\multicolumn{2}{|c|}{$\begin{array}{l}\text { NDVI-1 } \\
0.275-0.300\end{array}$}} & \multirow{2}{*}{\multicolumn{2}{|c|}{$\begin{array}{l}\text { NDVI-2 } \\
0.300-0.325\end{array}$}} & \multirow{2}{*}{\multicolumn{2}{|c|}{$\begin{array}{l}\text { NDVI-3 } \\
0325-0.350\end{array}$}} & \multirow{2}{*}{\multicolumn{2}{|c|}{$\begin{array}{l}\text { NDVI-1 } \\
0.35-0.40\end{array}$}} & \multirow{2}{*}{\multicolumn{2}{|c|}{$\begin{array}{l}\text { NDVI-2 } \\
0.40-0.45\end{array}$}} & \multirow{2}{*}{\multicolumn{2}{|c|}{$\begin{array}{l}\text { NDVI-3 } \\
0.45-0.50\end{array}$}} \\
\hline & & & & & & & & & & & & & \\
\hline & & Area (ha) & $(\%)$ & Area (ha) & $(\%)$ & Area (ha) & $(\%)$ & Area (ha) & $(\%)$ & Area (ha) & $(\%)$ & Area (ha) & $(\%)$ \\
\hline \multirow[t]{6}{*}{$0-10 \mathrm{~cm}$} & SC-1* & 0.00 & 0.00 & 0.00 & 0.00 & 0.79 & 43.89 & 0.32 & 29.36 & 0.33 & 16.34 & 0.16 & 15.69 \\
\hline & SC-2 & 0.28 & 54.90 & 1.79 & 98.35 & 0.99 & 55.00 & 0.73 & 66.97 & 1.46 & 72.28 & 0.84 & 82.35 \\
\hline & SC-3 & 0.23 & 45.10 & 0.03 & 1.65 & 0.01 & 0.56 & 0.04 & 3.67 & 0.23 & 11.39 & 0.00 & 0.00 \\
\hline & SC-4 & 0.00 & 0.00 & 0.00 & 0.00 & 0.00 & 0.00 & 0.00 & 0.00 & 0.00 & 0.00 & 0.00 & 0.00 \\
\hline & SC-5 & 0.00 & 0.00 & 0.00 & 0.00 & 0.01 & 0.56 & 0.00 & 0.00 & 0.00 & 0.00 & 0.02 & 1.96 \\
\hline & Total & 0.51 & & 1.82 & & 1.80 & & 1.09 & & 2.02 & & 1.02 & \\
\hline \multirow[t]{6}{*}{$0-30 \mathrm{~cm}$} & SC-1 & 0.00 & 0.00 & 0.00 & 0.00 & 0.00 & 0.00 & 0.00 & 0.00 & 0.00 & 0.00 & 0.00 & 0.00 \\
\hline & SC-2 & 0.00 & 0.00 & 0.00 & 0.00 & 0.85 & 47.22 & 0.31 & 28.44 & 0.38 & 19.10 & 0.16 & 15.24 \\
\hline & SC-3 & 0.15 & 30.00 & 1.30 & 71.04 & 0.93 & 51.67 & 0.60 & 55.05 & 1.03 & 51.76 & 0.74 & 70.48 \\
\hline & SC-4 & 0.34 & 68.00 & 0.53 & 28.96 & 0.00 & 0.00 & 0.17 & 15.60 & 0.58 & 29.15 & 0.13 & 12.38 \\
\hline & SC-5 & 0.01 & 2.00 & 0.00 & 0.00 & 0.02 & 1.11 & 0.01 & 0.92 & 0.00 & 0.00 & 0.02 & 1.90 \\
\hline & Total & 0.50 & & 1.83 & & 1.80 & & 1.09 & & 1.99 & & 1.05 & \\
\hline
\end{tabular}

* SC-1 (<1300 kPa), SC-2 (1300-1800 kPa), SC-3 (1800-2300 kPa), SC-4 (2300-2800 kPa) and SC-5 (>2800 kPa) 
Khalid Ali Al-Gaadi / American Journal of Agricultural and Biological Sciences 8 (1): 54-66, 2013

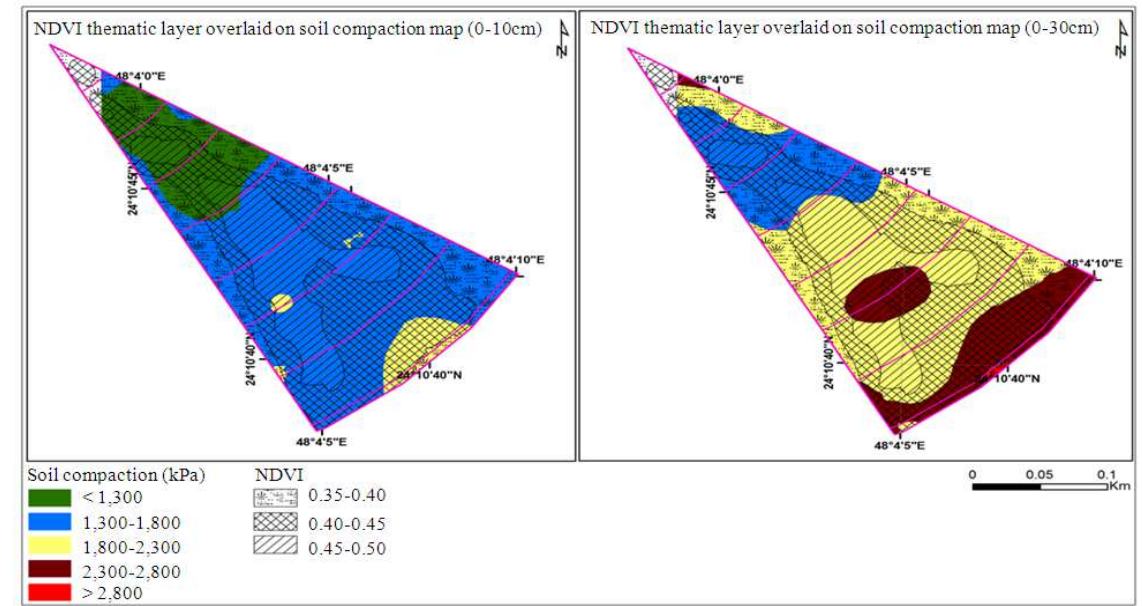

Fig. 10. Alfalfa March NDVI values overlaid on SC map

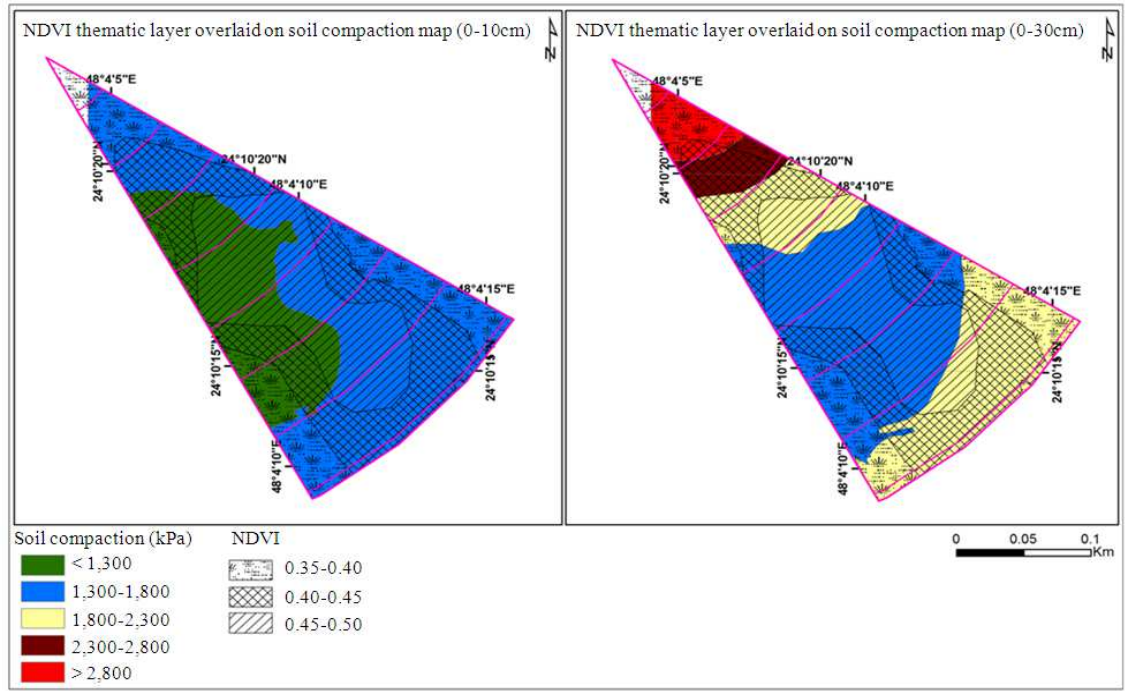

Fig. 11. Wheat February NDVI values overlaid on SC map

Table 4. Soil Compaction (SC) and NDVI intersected area statistics for wheat plot (TE11)

\begin{tabular}{|c|c|c|c|c|c|c|c|c|c|c|c|c|c|}
\hline \multirow[b]{4}{*}{ Soil Depth } & \multirow[b]{4}{*}{ SC zones } & \multicolumn{6}{|c|}{17 February, 2012} & \multicolumn{6}{|c|}{04 March, 2012} \\
\hline & & \multirow{2}{*}{\multicolumn{2}{|c|}{$\begin{array}{l}\text { NDVI-1 } \\
0.35-0.40\end{array}$}} & \multirow{2}{*}{\multicolumn{2}{|c|}{$\begin{array}{l}\text { NDVI-2 } \\
0.40-0.45\end{array}$}} & \multirow{2}{*}{\multicolumn{2}{|c|}{$\begin{array}{l}\text { NDVI-3 } \\
0.45-0.50\end{array}$}} & \multirow{2}{*}{\multicolumn{2}{|c|}{$\begin{array}{l}\text { NDVI-1 } \\
0.35-0.40\end{array}$}} & \multirow{2}{*}{\multicolumn{2}{|c|}{$\begin{array}{l}\text { NDVI-2 } \\
0.40-0.45\end{array}$}} & \multirow{2}{*}{\multicolumn{2}{|c|}{$\begin{array}{l}\text { NDVI-3 } \\
0.45-0.50\end{array}$}} \\
\hline & & & & & & & & & & & & & \\
\hline & & Area (ha) & $(\%)$ & Area (ha) & $(\%)$ & Area (ha) & $(\%)$ & Area (ha) & $(\%)$ & Area (ha) & $(\%)$ & Area (ha) & $(\%)$ \\
\hline \multirow[t]{6}{*}{$0-10 \mathrm{~cm}$} & SC-1* & 0.21 & 20.59 & 0.47 & 29.01 & 0.68 & 46.26 & 0.12 & 17.39 & 0.71 & 31.14 & 0.52 & 45.61 \\
\hline & SC-2 & 0.81 & 79.41 & 1.15 & 70.99 & 0.79 & 53.74 & 0.57 & 82.61 & 1.57 & 68.86 & 0.62 & 54.39 \\
\hline & $\mathrm{SC}-3$ & 0.00 & 0.00 & 0.00 & 0.00 & 0.00 & 0.00 & 0.00 & 0.00 & 0.00 & 0.00 & 0.00 & 0.00 \\
\hline & $\mathrm{SC}-4$ & 0.00 & 0.00 & 0.00 & 0.00 & 0.00 & 0.00 & 0.00 & 0.00 & 0.00 & 0.00 & 0.00 & 0.00 \\
\hline & SC-5 & 0.00 & 0.00 & 0.00 & 0.00 & 0.00 & 0.00 & 0.00 & 0.00 & 0.00 & 0.00 & 0.00 & 0.00 \\
\hline & Total & 1.02 & & 1.62 & & 1.47 & & 0.69 & & 2.28 & & 1.14 & \\
\hline \multirow{6}{*}{$0-30 \mathrm{~cm}$} & SC-1 & 0.00 & 0.00 & 0.00 & 0.00 & 0.00 & 0.00 & 0.00 & 0.00 & 0.00 & 0.00 & 0.00 & 0.00 \\
\hline & $\mathrm{SC}-2$ & 0.40 & 38.46 & 0.56 & 35.00 & 1.07 & 72.79 & 0.24 & 35.29 & 0.92 & 39.83 & 0.85 & 75.89 \\
\hline & SC-3 & 0.39 & 37.50 & 0.81 & 50.63 & 0.40 & 27.21 & 0.25 & 36.76 & 1.08 & 46.75 & 0.27 & 24.11 \\
\hline & SC-4 & 0.04 & 3.85 & 0.19 & 11.88 & 0.00 & 0.00 & 0.01 & 1.47 & 0.23 & 9.96 & 0.00 & 0.00 \\
\hline & SC-5 & 0.21 & 20.19 & 0.04 & 2.50 & 0.00 & 0.00 & 0.18 & 26.47 & 0.08 & 3.46 & 0.00 & 0.00 \\
\hline & Total & 1.04 & & 1.60 & & 1.47 & & 0.68 & & 2.31 & & 1.12 & \\
\hline
\end{tabular}

* SC-1 (<1300 kPa), SC-2 (1300-1800 kPa), SC-3 (1800-2300 kPa), SC-4 (2300-2800 kPa) and SC-5 (>2800 kPa) 


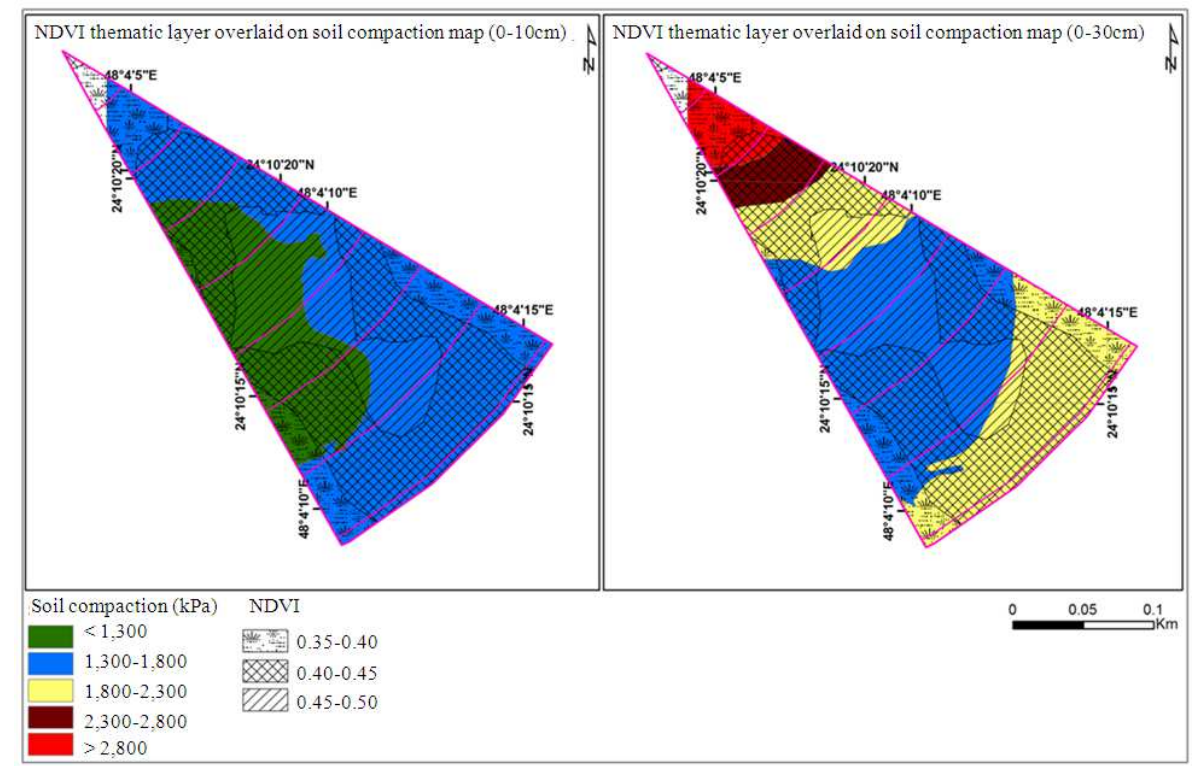

Fig. 12. Wheat March NDVI values overlaid on SC map

For the wheat crop at the soil depth of 0 to $30 \mathrm{~cm}$, the percentage of the area covered by the highest NDVI values (ranging from 0.45 to 0.50 ) that was associated with low SC values (less than $1800 \mathrm{kPa}$ ) was observed to be similar for both data sets, where it was 72.79 and $75.89 \%$ for February and March data sets, respectively (Table 4). Moreover, the distribution pattern of the NDVI over the compaction map was similar for both data sets (Fig. 11 and 12), where higher NDVI values were tagged to low SC values. The almost identical pattern shown in Fig. 11 and 12 suggested that the crop performance was either responsive to variations in $\mathrm{SC}$ at both growth stages or independent of the SC at the soil depths considered in the study. The low correlation between wheat NDVI and SC shown in Fig. 8 and Table 2 promoted the probability that the crop performance was not affected by SC at the considered soil compaction levels and soil depth at which compaction was determined (Arvidsson et al., 2012).

\section{CONCLUSION}

A field study was conducted to investigate the soil compaction under center pivot irrigation system and its impact on crop performance. The specific conclusions drawn from the study are as follows:

- Significant spatial variation of Soil Compaction (SC) of more than $1000 \mathrm{kPa}$ was observed within each of the tested plots. This variation introduced the need for a precision agriculture technique and engineering procedures that adopt discriminative field management based on field SC spatial variation

- On the average, the alfalfa field showed higher compaction values (1730.33 and 2329.60 at soil depth of 0 to 10 and 0 to $30 \mathrm{~cm}$, respectively) compared to those observed in the wheat field (1339.67 and 2088.90 at soil depth of 0 to 10 and 0 to $30 \mathrm{~cm}$, respectively). That was attributed to the fact that the alfalfa was a multi-cut crop demanding more field operations, hence more traffic and SC

- No significant lateral SC was found due to pivot wheel tracks. The values of the Coefficient of Variation (CV) of the average SC values around wheel tracks were below $17 \%$

- For the alfalfa crop, the inverse proportional relationship between the crop performance, expressed as the Normalized Difference Vegetation Index (NDVI) and SC was found to be significant $(\mathrm{P}<0.05)$ at all test conditions. On the other hand, the wheat crop NDVI was found to be not significantly related to $\mathrm{SC}(\mathrm{P}>0.05)$

- Using GIS software program and remotely-sensed satellite data, GIS maps of SC and crop NDVI were developed. Spatial analysis showed that for alfalfa crop, $47.22 \%$ of the area covered by the highest NDVI values $(0.325-0.350)$ was associated with low $\mathrm{SC}$ values $(\leq 1800 \mathrm{kPa})$ at the early crop growth 
stage (February data); however, this association became lower $(15.24 \%)$ at later crop growth stage (March data). For the wheat crop, the distribution of NDVI values was not affected by SC at both growth stages; therefore, this crop was said to be insensitive to soil compaction levels investigated in this study

- Mapping of SC and crop NDVI can provide a better understanding of the spatial variability of compacted areas within a specific field and its effect on a specific crop performance. As a result, it can greatly help farmers determine where and when to till or subsoil their fields and the machines and energy required. SC mapping is considered as the first step towards the application of a precision variable tillage, where tillage is tailored to fit the different requirements of different field locations

\section{REFERENCES}

Arvidsson, J., I. Hakansson and C. Pettersson, 2012. Sensitivity of different crops to soil compaction. Proc. NJF Seminar, 6: 37-40.

Bawazir, A.S., Z. Samani, M. Bleiweiss, R. Skaggs and T. Schmugge, 2009. Using ASTER satellite data to calculate riparian evapotranspiration in the middle Rio grande, New Mexico. Int. J. Remote Sens., 30: 5593-5603. DOI: 10.1080/01431160802695683

Bober, M.L., D. Wood and R.A. McBride, 1996. Use of digital image analysis and GIS to assess regional soil compaction risk. Photogrammetric Eng. Remote Sens., 62: 1397-1404.

Braunack, M.V., J.E. McPhee and D.J. Reid, 1995. Controlled traffic to increase productivity of irrigated row crops in the semi-arid tropics. Australian J. Exp. Agric., 35: 503-513. DOI: 10.1071/EA9950503

Bruand, A., C. Hartmann and G. Lesturgez, 2005. Physical properties of tropical sandy soils. Int. Agrophysics, 17: 61-69.

Childs, C., 2004. Interpolating surfaces in ArcGIS spatial analyst. ArcUser,

Domsch, H., D. Ehlert, A. Giebel, K. Witzke and J. Boess, 2006. Evaluation of the soil penetration resistance along a transect to determine the loosening depth. J. Precision Agric., 7: 309-326. DOI: $10.1007 / \mathrm{s} 11119-006-9009-6$

Hannaway, D.B. and C. Larson, 2004. Forage fact sheetalfalfa. Oregon State University, USA.

Isaac, N., R. Taylor, S. Staggenborg, M. Schrock and D. Leikam, 2002. Using cone index data to explain yield variation within a Field. Int. Commission Agric. Eng.
Kulkarni, S.S. and S.G. Bajwa, 2005. Spectral response of cotton canopy to soil compaction. ASAE.

Kulkarni, S.S., S.G. Bajwa and G. Huitink, 2010. Investigation of the effects of soil compaction in cotton. Trans. ASABE.

Lipiec, J., 2012. Crop responses to soil compaction. Helsinki, Finland, 6-8: 27-36.

Lipiec, J., V.V. Medvedev, M. Birkas, E. Dumitru and T.E. Lyndina et al., 2003. Effect of soil compaction on root growth and crop yield in Central and Eastern Europe. Int. Agrophysics, 17: 61-69.

Lu, D., P. Mausel, E. Brondizio and E. Moran, 2002. Assessment of atmospheric correction methods for Landsat TM data applicable to Amazon basin LBA research. Int. J. Remote Sensing, 23: 2651-2671. DOI: $10.1080 / 01431160110109642$

OmniSTAR, 2010. 9200-G2 User Manual. OmniSTAR B.V.

Patil, V.C. and K.A. Al-Gaadi, 2012. Precision fertigation in wheat for sustainable agriculture in Saudi Arabia. Proceedings of the 11th International Conference on Precision Agriculture, Jul. 15-18, Indianapolis, Indiana, USA.

Petcu, G. and E. Petcu, 2006. Effect of cultural practices and fertilizers on sunflower yields in long term experiments. HELIA, 29: 135-144.

Pritchard, F., J. Fitzpatrick, K. Hobson and M. Imhof, 2009. Physical constraints to root growth. In: Identifying, understanding and managing hostile subsoils for cropping: A reference manual for neutral-alkaline soils of south-eastern Australia. The Profitable Soils Group.

Rechel, E.A., B.D. Meek, W.R. DeTar and L.M. Carter, 1991. Alfalfa yield as affected by harvest traffic and soil compaction in a sandy loam soil. J. Prod. Agric., 4: 241-246.

Richard, G., H. Boizard, J. Roger-Estrade, J. Boiffin and J. Guerif, 1999. Field study of soil compaction due to traffic in northern France: Pore space and morphological analysis of the compacted zones. Soil Tillage Res., 51: 151-160. DOI: 10.1016/S01671987(99)00058-6

Rundquist, B.C. and J.A. Harrington, 2000. The effects of climatic factors on vegetation dynamics of tallgrass and shortgrass cover. Geocarto Int., 15: 3338. DOI: $10.1080 / 10106040008542161$

Smith, A.M.S., 2007. How to convert ASTER radiance values to reflectance: An online guide. University Idaho.

Sun, Y., H. Druecker, E. Hartung, H. Hueging and Q. Cheng et al., 2011. Map-based investigation of soil physical conditions and crop yield using diverse sensor techniques. Soil Tillage Res., 112: 149-158. DOI: $10.1016 /$ j.still.2010.12.002 
Tatura, D.P.I., 2005. Centre pivot wheel rutting. Department of Primary Industries.

Tracy, B.F. and Y. Zhang, 2008. Soil compaction, corn yield response and soil nutrient pool dynamics within an integrated crop-livestock system in Illinois. Crop Sci., 48: 1211-1218. DOI: 10.2135/cropsci2007.07.0390

Tucker, C.J., D.A. Slayback, J.E. Pinzon, S.O. Los and R.B. Myneni et al., 2001. Higher northern latitude normalized difference vegetation index and growing season trends from 1982 to 1999 . Int. J. Biometeorol., 45: 184-190. DOI: 10.1007/s00484001-0109-8

USDA, 1997. Chapter3-Crops. In: National Engineering Handbook-Irrigation Guide, USDA, USA.
Vermeulen, G.D., J.N. Tullberg and W.C.T. Chamen, 2010. Controlled Traffic Farming. In: Soil Engineering, Soil Biology 20, Dedousis A.P. and T. Bartzanas, (Eds.), Springer-Verlag Berlin Heidelberg, pp: 101-120.

Wells, L.G., T.S. Stombaugh and S.A. Shearer, 2001. Application and assessment of precision deep tillage. ASAE Annual Int. Meeting, 1: 1-16.

Yuksel, A., A.E. Akay and R. Gundogan, 2008. Using ASTER imagery in land use/cover classification of eastern Mediterranean landscapes according to CORINE land cover project. Sensors, 8: 1237-1251. DOI: $10.3390 / \mathrm{s} 8021287$ 